\title{
Berliner Erklärung fordert Geschlechtergerechtigkeit bei Führungspositionen
}

Berlin, den 02. März 2012

An

die Unterzeichnerinnen und Unterzeichner der Berliner Erklärung

Sehr geehrte Damen und Herren,

die Berliner Erklärung hat innerhalb kurzer Zeit mehr als 12.000 Unterstützerinnen und Unterstützer gewonnen. Das ist ein großer Erfolg, zu dem auch Sie mit Ihrer Unterschrift beigetragen haben. Dafür bedanken wir uns sehr herzlich!

Wir sammeln weiter Unterschriften - und brauchen davon noch viele Tausend. Denn wir wollen ein breites gesellschaftliches Bündnis schmieden, um dadurch die Mehrheit der Abgeordneten im Deutschen Bundestag für eine gesetzliche Quote für Frauen in Aufsichtsräten zu gewinnen.

Momentan fehlt uns diese Mehrheit. Noch meinen zu viele, bei einer solchen Quote ginge es um eine Luxusforderung für wenige privilegierte Frauen. Zu wenige sehen, dass die gesetzliche Quote nur ein erster Schritt hin zu gleicher Teilhabe von Frauen in allen gesellschaftlichen Bereichen ist.

Deshalb bitten wir Sie sehr herzlich, weiter für die Berliner Erklärung zu werben. Gewinnen Sie mit uns gemeinsam noch mehr Menschen, sprechen Sie mit Kolleginnen und Kollegen, mit Freunden und Bekannten, im Verein und in Ihrer Familie.

Mit einer Unterschrift unter www.berlinererklaerung.de, per Post oder Fax kann jede und jeder helfen, gleiche Teilhabe von Frauen zu verwirklichen, Gleichstellung voran zu bringen und unsere Demokratie lebendiger zu machen.

Für Ihr Engagement danken wir Ihnen herzlich!

Dorothee Bär, MdB

Cornelia Möhring, MdB

Rena Bargsten, EWMV

Brigitte Scherb, dlv
Ekin Deligöz, MdB

Rita Pawelski, MdB

Carlotta Köster-Brons, VdU

Monika Schulz-Strelow, FidAR
Sibylle Laurischk, MdB

Dagmar Ziegler, MdB

Ramona Pisal, djb

Henrike von Platen, BPW Germany

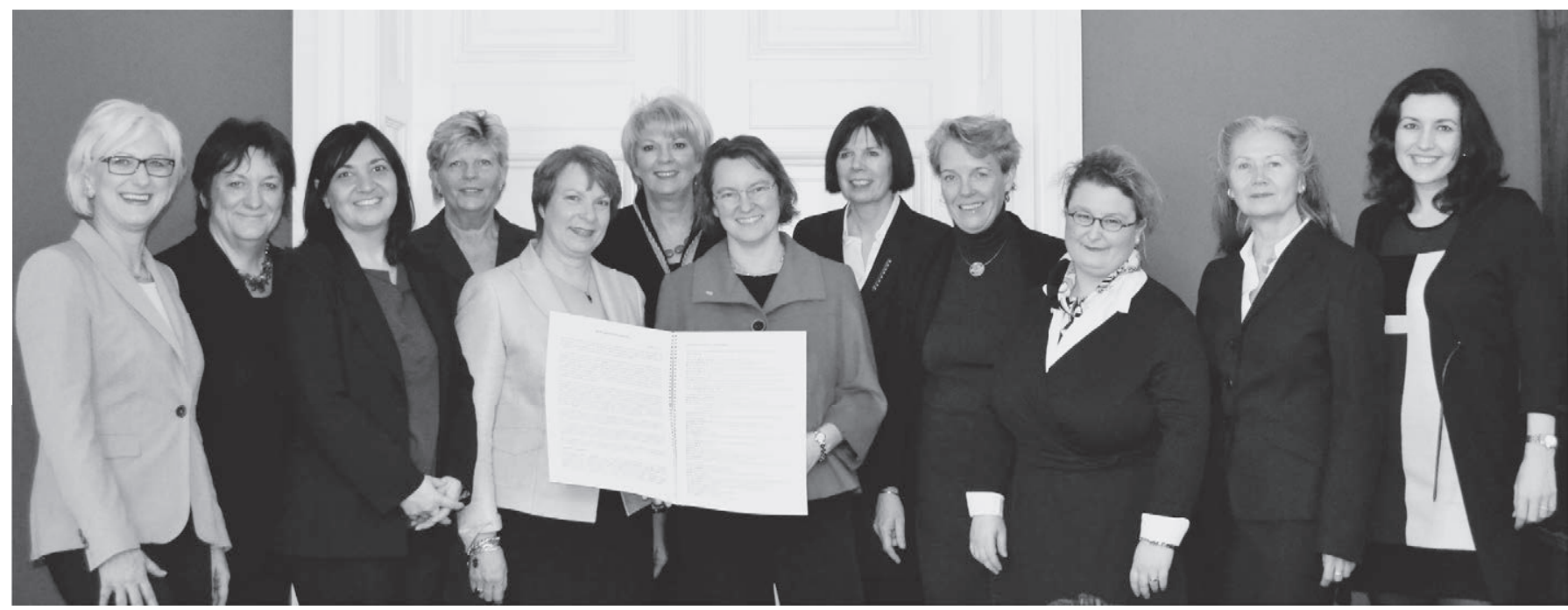

A Auftakt am 15. Dezember 2011 für überparteiliche Initiative von Frauenverbänden und Parlamentarierinnen für mehr Chancengleichheit in der Wirtschaft: Abgeordnete aller sechs im Bundestag vertretenen Parteien und die Vertreterinnen sechs großer Frauenverbände - darunter der djb - fordern in der Berliner Erklärung die tatsächliche Durchsetzung der im Grundgesetz garantierten Gleichberechtigung von Frauen und Männern und die Beseitigung bestehender Nachteile für weibliche Karrieren. 